\title{
A Study of Patellofemoral Pain in a Junior Infantry Training Unit
}

\author{
Capt K C M Wilson*
}

$M B, C h B, R A M C$

Infantry Junior Leaders Bn., Shorncliffe

\section{Mrs E Evans-Smith}

Mr B J Oelman**

MSc

Ministry of Defence, (Stats $(G) 4)$, Stanmore

SUMMARY: The incidence of patellofemoral pain in a Junior Unit was assessed retrospectively over a 4 year period and prospectively by studying an annual intake of recruits during their initial training year. An average of $3.5 \%$ per intake were found to have been discharged due to the disease between 1977 and 1980 . $4.5 \%$ of the intake prospectively studied were discharged and $75 \%$ of those presenting with symptoms were cured.

The clinical characteristics of recruits presenting with the the disorder were prospectively studied in a con trolled, blind, consecutive series of 45 patients. Two groups of characteristics were identified; those with an 은 early, insidious onset in training, a pre-Service history and a poor response to physiotherapy and thos@ with an acute, traumatic onset, presenting later in training and responding well to physiotherapy. The $c$ aetiology of patellofemoral pain in a Junior Recruit is discussed and attention drawn to specific problems cncountered by these patients.

\section{Introduction}

A comprehensive survey of the literature has shown patellofemoral pain to be a common disorder in civilian and military populations. The incidence of the disease as diagnosed at meniscectomy was found to peak in the 20 to 29 age group, becoming less frequent in later life'. This has been demonstrated in a study on Army personnel diagnosing the disorder on a clinical basis and illustrating the severity of the problem in Her Majesty's Forces ${ }^{2}$. Fulford ${ }^{3}$ in a study of naval ratings and marines has found a relationship with hard physical work, a pre-requisite of the Junior Infanteer's training.

There is considerable confusion expressed in the literature 4,5 in the aetiology and nomenclature of pathological entities and syndromes relating to the patella. The disorders commonly presenting in the junior soldier are discussed. Relationships between the conditions are examined in the context of aetiology, pathology and presentation in a junior unit.

\section{Chondromalacia Patellae}

Chondromalacia is recognised as a well defined

- Now at Queen Elizabeth Military Hospital, Woolwich

" Now at Department of Transport syndrome of pain in the anterior part of the knee The diagnostic reliability of the clinical presentation has been substantiatel by Zollinger ${ }^{7}$, confirmatoß diagnoses being made by arthroscopy. As describect by Outerbridge ${ }^{4}$ there are four grades of macroscopic change of the patella cartilage in chondromalacia, $\frac{\circ}{\circ}$ ranging from softening and swelling (Grade 1) to $\complement$ erosion down to the bone (Grade 4). The aetiology $\overrightarrow{\overrightarrow{0}}$ of this condition may be explained by a ridge of 3 cartilage on the medial femoral condyle ${ }^{8,9}$ but this causative relationship has recently been refuted ${ }^{10}$. Ficet et $\mathrm{al}^{8}$ classify chondromalacia topographically and postulate that the location of the lesion reflects the pathophysiology and consequently the biomechanical solutions of the conditions.

Lastly, Goodfellow et al11 distinguished between $\cong$ surface cartilage degeneration, common on the medial patella facet, associated with ageing and basal de- $\frac{}{3}$ generation which is pathological and symptomatic. None of these classification systems of chondroma- $\frac{3}{3}$ lacia are mutually exclusive and each postulates an inherent, structural or biomechanical predisposition to the disorder which may be corrected surgically. $\frac{D}{0}$

\section{Osteoarthritis}

Osteoarthritis tends to be found in older agen groups $^{12}$ as diagnosed radiologically by joint space 
narrowing, sclerosis and spurring ${ }^{13}$. Its relevance in the junior soldier is discussed as Outerbridge ${ }^{1}$ and others $^{14}$ postulate that it and chondromalacia are manifestations of the same disease, osteroarthrosis being the same as grade 4 chondromalacia. There is evidence demonstrating similar vascular changes in the two disorders ${ }^{15}$ and similarities have been found radiologically ${ }^{16}$ tending to support a common patholugy. However, Abernethy et $\mathrm{al}^{17}$ and other authors $^{18} 19$ state that the conditions should be differentiated, chondromalacia being a transient, often non-symptomatic fibrillation of the articular cartilage. The relationship between the disorders as defined by direct access to the patella cartilage and radiology is still being debated. The arguments cause confusion in aetiology and nomenclature which are, in turn, reflected in treatment regimes, medical recording and research.

\section{Osteochondritis}

Osteochondritis, consisting of a loose osteochondral fragment may be diagnosed radiologically ${ }^{12}$. In the junior soldier it is a relatively uncommon disorder but may present with trauma and subsequent post-traumatic osteoarthrosis.

\section{Trauma}

Direct trauma to the patella is a frequent occurrence in the junior infanteer, as in skirmishing practice where it can be specifically minimised in emphasising the protection of the knees by extending the arm to take the body load on falling to the ground. Trauma and osteochondral fracture are frequent precursors of chondramalacia, $75 \%$ of cases with clinical chondromalacia patellae presenting with this history of onset ${ }^{20}$. A causative association is challenged in Repo's study of the survival of articular cartilage after controlled impact ${ }^{21}$, where it is noted that a purely compressive impact as in the "dashboard injury" presenting a femoral fracture, does not cause cartilage damage.

\section{Over-use Syndrome}

Over-use syndrome in young athletes may be classified as a separate entity ${ }^{12}$, microhondral fractures of the patella being postulated as a pathology in these cases $^{22}$. This may be a cause of confusion as chondromalacia patella is seen as a clinical presentation in this population ${ }^{2}{ }^{3}{ }^{23}$. In the context of the Army where physical fitness is encouraged ${ }^{24}$ the relationship between trauma, over-use syndromes and chondromalacia become difficult to unravel either clinically or surgically.

\section{Quadriceps Dysplasia and Mal-alignment Syndrome}

The patella-mal-alignment syndrome, resulting in lateral patella tracking ${ }^{25}$ and excessive lateral pressure syndrome ${ }^{26}$ may well cause chondromalacia patella and recurrent subluxation. The two entities being $z$ manifestations of the same disease ${ }^{2 \tau}$. The mal-align- $\stackrel{\Phi}{\infty}$ ment syndrome may be a direct result of quadriceps dysplasia $^{28}$ and is associated with a high riding $O$ patella $^{20}$. Williams ${ }^{25}$ emphasises the role of vastus medialis and quadriceps reversal in the aetiology of chondromalacia patella and developing this, Reider et $\stackrel{0}{+}$ $\mathrm{al}^{29}$ suggests that subluxation dislocation and chondromalacia should be re-designated as quadriceps 음 dysplasia; one, two and three. There is no doubt $\frac{5}{\square}$

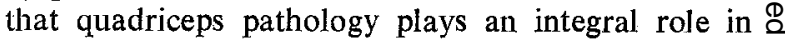
chrondromalacia patella and consequently rest and physiotherapy play a crucial role in the initial management of the disease ${ }^{6}, 12,14$.

Other conditions ${ }^{12}$ which may present as patello- $\vec{\omega}$ femoral pain in the young soldier and athlete include $\stackrel{S}{?}$ peri-patella epiphisitis, tendonitis and rarely sympathetic dystrophy which may be diagnosed radiologically ${ }^{26}$.

It is evident from this brief review that the concept of single pathology, patello-femoral pain should be 0 viewed with some suspicion. The relationships be: tween chondromadacia, osteoarthritis the over-use syndrome, trauma, mal-alignment and quadriceps dis. orders are profoundly complex, resulting in confused nomenclature and difficulties in assessing the role of each in the presentation of the junior soldier wit⿱艹 patello-femoral pain. Non-surgical management of junior soldiers presenting with patello-femoral pain will not always be appropriate. This study is designed to demonstrate the incidence of the syndrome in junior training unit and identify the clinical presents tion of those patients who will need surgical investigation and treatment.

\section{Materials and Methods}

Population: The study population consisted of junior soldiers, 16 years old, recruited nationwide and all taking part in a pre-structured military training programme of 12 months duration. Each patient was asymptomatic and passed medically fit by two independent medical examinatious at initial recruitment.

Retrospective Study: The incidence of patellofemoral disease as a cause of medical discharge from the Unit between 1977 and 1980 was determined retrospectively. The medical records pertaining to medical discharges due to the condition as diagnosed by the Unit Medical Officer and confirmed by a Specialist were identified. The number of recruits in each intake during this period were recorded and the percentage discharge per intake calculated.

Prospective Studies: A more detailed prospective study of the extent of the disease current in at Battalion was carried out. The study followed 500 re. 
cruits through the initial year of training. Soldier's personal details and training progress were recorded, as were the recruits' medical management and fina ldisposal, if presenting with patellofemoral disease. The incidence of the clinical disease, cure rates and referral rates were recorded from each Company in the Battalion.

Following a pilot study a prospective, double blind siudy was carried out, its aim to identify the clinical sub-groups presenting with patello-femoral pain. A consecutive series of 45 recruits presenting with the syndrome and a random control sample of 50 recruits were studied. Details of symptoms, mode of onset and representative support, pre-enlistment and during training were documented in both groups. Treatment and outcome were recorded under double blind conditions.

In both prospective studies patellofemoral pain was diagnosed on clinical grounds as expressed in the literature, ${ }^{0}$ diagnostic signs were :

(a) Pain induced on extension of knee against resistance.

(b) Pain on gentle manipulation of patella over the femoral condyles and resistance of this movement.

(c) Condyles and resistance of this movement.

(c) The patella apprehension test (positive).

(d) Pain on quadriceps contraction against mild, distally directed pressure on the patella.

Symptoms diagnostic of pre-service and service disease were:

(a) Pain on stair walking ${ }^{30}$.

(b) Pain or stiffness associated with rest and after sport $^{6}$.

(c) History of dislocation of the patella ${ }^{13}$.

(d) Feeling of giving way or instability of the knee ${ }^{14}$.

Only if a recruit was unable to run 50 metres and failed to maintain peer group standards of training was he included in the study group as a sufferer of patellofemoral pain.

Treatment was standardised; each patient attended physiotherapy for one hour each weekday for a fiveweek pre-structured physiotherapy regime similar to that advocated by Williams, ${ }^{31}$ consisting of radiant heat and rest, progressive quadriceps faradism and isosometric quadriceps extension exercise. Two grams of soluble aspirin were taken daily by each patient in divided doses. ${ }^{32}{ }^{33}$. All other activity was curtailed apart from swimming in the fourth and fifth week.

Cure was defined as the absence of signs and symptoms over a minimum of two months of strenuous physical training and a series of combat fitness tests.

Contingency tables were used in statistical analysis. shown in Table 1. The percentages are of the total intake of recruits, there is an immediate $30-50$ per

\section{Results}

Incidence: The incidence of patellofemoral disease as a cause of discharge between 1977 and 1980 are cent discharge of recruits due to homesickness and personal reasons in the first month of training.

Table I

Information from unit and personal records

\begin{tabular}{lccc}
\hline $\begin{array}{l}\text { Month of } \\
\text { intake }\end{array}$ & $\begin{array}{c}\text { No of } \\
\text { recruits on } \\
\text { intake }\end{array}$ & $\begin{array}{c}\text { Nos of dis- } \\
\text { charges due } \\
\text { to P-F pain }\end{array}$ & $\begin{array}{c}\% \\
\text { Discharged }\end{array}$ \\
\hline June 1977 & 129 & 2 & 1.50 \\
Sept 1977 & 598 & 7 & 1.17 \\
June 1978 & 220 & 6 & 2.72 \\
Sept 1978 & 533 & 6 & 1.13 \\
Mar 1979 & & & 2.15 \\
June 1979 & 279 & 6 & 5.00 \\
Sept 1979 & 440 & 22 & 5.80 \\
Mar 1980 & 51 & 3 & 7.62 \\
June 1980 & 233 & 17 & 3.00 \\
Sept 1980 & 526 & 16 & \\
\hline
\end{tabular}

The results of the prospective study of 500 recruit are shown in Table II. The percentages have bee⿳⺈⿴囗十 adjusted in this case to accommodate other caus of discharge and consequently illustrate the percentage of recruits failing to pass adult service because patellofemoral disease alone.

Table II

Outcome and presentation percentages of recruits suffering from Patello-Femoral disease from an intake of 500 junior soldiers

\begin{tabular}{|c|c|c|c|c|c|c|}
\hline Company & 1 & 2 & 3 & 4 & 5 & $\overline{\text { Battalion }}$ \\
\hline$\%$ of company & 21.5 & 25.8 & 15.3 & 15.4 & 18.0 & 18.8 \\
\hline $\begin{array}{l}\text { cured } \\
\text { of company }\end{array}$ & 64.0 & 93.7 & 60.0 & 69.0 & 84.0 & 75.0 \\
\hline uncured & 7.6 & 1.38 & 6.1 & 4.7 & 2.7 & 4.5 \\
\hline
\end{tabular}

Percentages have been adjusted to allow for other causes for discharge

We were particularly aware of the possibility of recruits presenting with symptoms or over emphasis- 3 ing their disorder to avoid unpleasant or arduous tasks in training. (A common occurrence in a junior training battalion.) In order to examine this hypothesis the Company percentage cure rates were plot- $J$ ted against the Company percentage presentation $\frac{}{0}$ rates; a non significant correlation of $66 \%$ was found. When the Company percentage discharge was plotted $N$ against the percentage presentation rate, a negative $N$ correlation of $41.3 \%$ was found, again non significant. N 
Clinical Characteristics: The prospective study of 45 recruits and control group demonstrated that none of the control group were found to have a preservice history of patellofemoral pain, while $28 \%$ of those with a service attack did. $(\mathrm{p}<0.01)$. If a recruit had played pre-service sport he was less likely to present with patellofemoral pain during the year of initial training $(65 \%)$ then if he had not played pre-service sport $(77 \%)$. This result is just significant at the $5 \%$ level.

The results of the study of the consecutive series of 45 recruits presenting with patellofemoral pain demonstrated three main determinants of clinical profile :

1. The mode of onset; acute and traumatic or insidious and progressive with no noticeable preceding trauma.

2. Pre-service history of symptoms of patellofemoral disease.

3. The response of symptoms and signs of physiotherapy.

These are illustrated in Table III.

A more detailed analysis of these results demonstrates that the two numerically predominant groups in the table are statistically significant. Recruits with a pre-service history are less likely to be cured than those without. $(\mathrm{p}<0.001)$ Recruits with a preservice history are more likely to have an insidious onset whereas those without are more likely to have an acute traumatic onset. $(p<0.001)$ An initial, acute onset of symptoms (whether service or pre-service) is more likely to be cured than those with an insidious onset. $(\mathrm{p}<0.001)$ More specifically, those with no preservice history and an acute onset are more likely to be cured than those with an insidious onset. $(p<05)$ The lack of patients with an insidious onset and no pre-service history makes this less reliable, this is significant in itself.

\section{Table III}

Therapeutic outcome related to presservice history and mode of onset of Patello-Femoral pain

\begin{tabular}{llrr}
\hline & & Cured & Uncured \\
\hline $\begin{array}{l}\text { Preservice } \\
\text { history } \\
\text { experienced }\end{array}$ & $\begin{array}{l}\text { Acute traumatic } \\
\text { No }\end{array}$ & 3 & 1 \\
preservice & Insidious onset & 2 & 10 \\
history & $\begin{array}{l}\text { Acute traumatic } \\
\text { onset }\end{array}$ & 22 & 2 \\
Insidious onset & 2 & 3 \\
\hline
\end{tabular}

An unavoidable variant in the treatment regime was a random insertion of three weeks leave. During the leave period rest was encouraged, medication continued and physiotherapy stopped. Forty two per cent of cases where the patient went on leave during treatment were cured, whilst $92 \%$ of those not going on leave were cured. The difference is statistically significant (p. 05).

The two main groups of clinical presentation were plotted against the time of onset in relation to the year's training. Figures 1 and 2 demonstrate that the majority of those with a pre-service history, insidious onset and failure to respond to physiotherapy presented earlier in their training. Those with a traumatic, acute onset and no pre-service history presented nearer the end of their training.

\section{Conclusion}

The aims of this study are threefold; to demonstrate the incidence of patellofemoral pain in a Junior Infantry Training Unit, to identify the clinical characteristics of the syndrome and to draw attention to the specific problems facing a symptomatic soldier in the context of his training and management.

The retrospective study of medical discharge due to the condition was hampered by incomplete medical records. Consequently the average (approximate) $3.5 \%$ discharge of each intake is likely to be an underestimate. The medical documents of 1977 an $\$$ 1978 were particularly incomplete as reflected in the figures. The prospective assessment of disease in: cidence is more informative: in the year studied

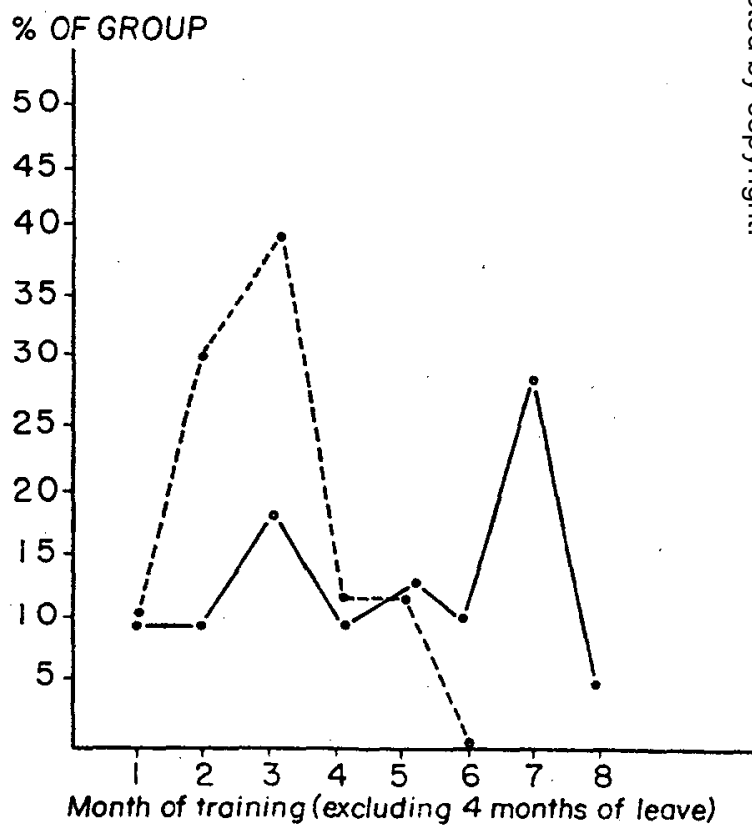

Fig. $1 \%$ of recruits presenting in each month

- - Group of pre-service history, insidious onset, not cured

- Group of no pre-service history, acute onset cured 


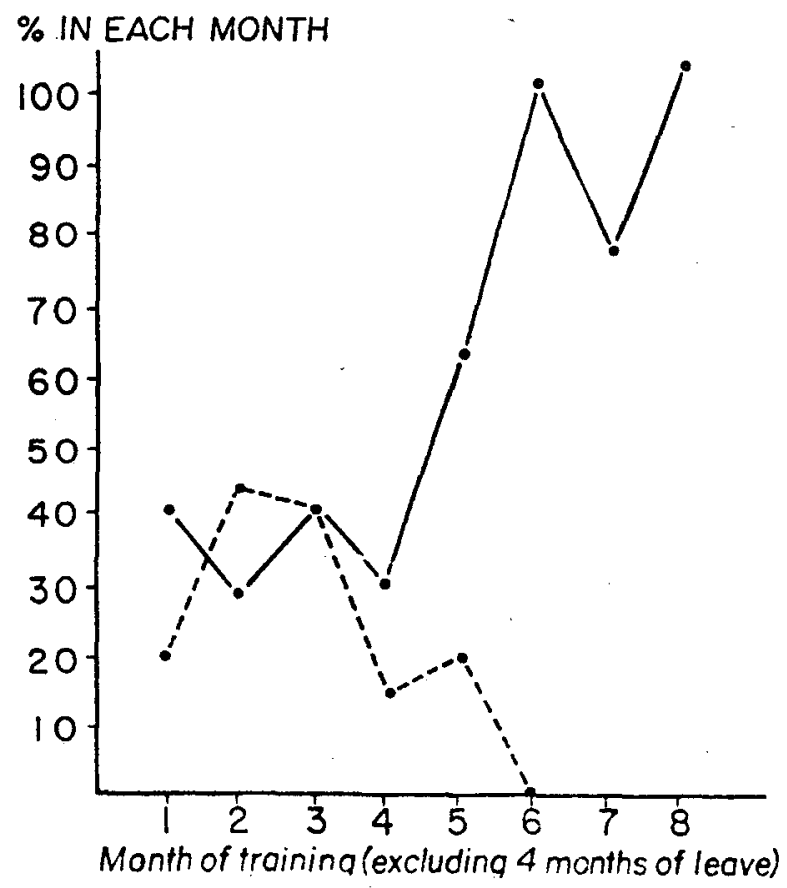

Fig. $2 \%$ of recruits presenting in each month in each group.

$18.8 \%$ of potential adult soldiers presented with the syndrome. Of these $75 \%$ were cured by physiotherapy, the remainder eventually being discharged after specialist consultation and treatment. These represented $4.5 \%$ of the study group.

In examining the characterisitics of the syndrome two clinical sub-groups were identified: firstly, those presenting early in training with a pre-service history, insidious onset, failure to respond to physiotherapy and eventual discharge. Secondly, those presenting later in the year with no pre-service history, acute, trauma related onset and a good response to physiotherapy. We postulate that those in the first group have an inherent tendency to present with patellofemoral pain as has been shown in the case of chondromalicia and subluxation of the patella. ${ }^{34}$ This tendency was clinically manifest pre-service and re-presents on commencement of Army training. Those in the acute onset group do not have the same tendency to patellofemoral disease and present later in training, following trauma, when physical fitness and field training are of high priority. As they do not have a premorbid biomechanical or structural abnormality they respond to conservative treatment and tend not to re-present.

This hypothesis is supported by two further clinical findings: firstly, a recruit is more likely to develop service patellofemoral pains if he has a pre-service history. $(P<0.01)$. Secondly, if a recruit played preservice representative sport he is less likely to present with patellofemoral pain in service. (Significant at the $5 \%$ level). The relevance of this can be explained by응 those with a syndrome predisposition and a pre-service history are less likely to expose themselves to $\Rightarrow$ the trauma of sport. Our study was too small to vali- $\underset{+}{+}$ date this hypothesis statistically.

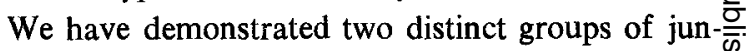
ior soldiers presenting with patellofemoral pain. Two $\overrightarrow{\widetilde{\sigma}}$ variables which were considered relevant in determin- $\varrho$ ing the clinical profile of the syndrome were examin-w ed: firstly, there was a random interruption of the $\overrightarrow{0}$ physiotherapy course by three weeks vacation in some:cases. Recruits for whom the treatment was inter- $\vec{\omega}$ rupted were less likely to be cured than those who? had an uninterrupted course. This would suggest that active physiotherapy as we have described it mayp play an important role in the treatment of the syn- $\vec{N}$ drome. Secondly, it was postulated that recruits were? exaggerating symptoms in order to avoid duties. AN tendency for company cure rates to increase as pêfsentation rate increased was demonstrated. This mighto be expected if one assumed a constant rate of disease across all companies with some personnel exagger ing symptoms and eventually being "cured." Q⿱ constant discharge rate, irrespective of presentation rate would be expected. This was not the case, $\mathrm{O}^{\mathrm{a}}$ negative correlation was demonstrated. Neither of $\overrightarrow{\mathrm{fo}}$ these correlations are statistically significant but whet trends there are suggest the hypothesis is false ando that other factors determine the presentation, do charge and cure rates of the company.

This study has demonstrated that patellofemora pain is a major clinical entity in this junior unit. $A \stackrel{\mathbb{Q}}{\stackrel{2}{2}}$ number of pathologies present as the syndrome but those recruits that are going to be discharged as $\$$ result of the condition can be identified by clinicaE examination and careful history taking. As demon? strated in the recruits, this insidious onset group represents $25 \%$ of cases in civilian life. ${ }^{28}$ It is eviden that the medical screening system for recruit selection is inadequate. As the diagnosis is primarily a clinica one, a case can be made for increased teaching empha sis of future Unit Medical Officers and those involved $\vec{P}$ in reciruitment medical examinations with particula reference on the significance of pre-service symptoms.

The junior soldier, not responding to physiotherapy을 on the specialist waiting list, or waiting for medicab board proceedings, presents a problem for the unit During the study it was a common occurance for thiso waiting period to be greater than three months. The main causes of delay were the waiting list and proce $O$ dural delays in discharge. A considerable output in finance and man hours were spent in supporting thesev 
redundant soldiers, a fall in their individual and peer morale was evident. Necessarily the recruit's family has to readapt and reorganise home life to accommodate a returning boy. A new occupation must be sought with the added handicapping label of an Army Medical Discharge.

It is evident that our screening systems are faulty and that a reassessment of the priority for a junior recruit with this pre-service disease should be made if these problems are to be resolved.

\section{REFERENCES}

1 Outtraridge $R$ E. The Aetiology of Chondromalacia Patellae. J Bone Jt Surg. 1961; 4.43B: 752757.

2 RoBinson A R, DARracotT J. Chondromalacia Patellae Ann Phys Med 1970; 10: 286.

3 Fulford P C. Chondromalacia Patellae. A disease of the Active. Br J Sports Med 1969; 4: 198-202.

4 Rubacy G E. Correspondence. J Bone Jt Surg 1982; 64A: 4-633.

5 WILson K. Chondromalacia Patella. Correspondence $\mathrm{Br}$ Med J 1981; 282: (6273) 1400.

6 Gruber M A. The Conservative Treatment of Chondromalacia Patellae. Symposium on Disorders of the Knee Joint. Orth Clin $N A m$ 1979; 10: $105-115$.

7 Zollingrr H., Schmohl P. Arthroscopy and Patella Chondropathy Endoscopy. 1980; 12: 265-268.

8 OUTERBRIDGE R E. Further studies on the Aetiology of Chondromalacia Patella. J Bone Jt Surg 1954; 46B: 179-190.

9 Mackenzie Crooks L. Chondromalacia Patella. Early results of a Conservative Operation. $J$ Bone Jt Surg 1967; 46B 3: 495-501.

10 WARD CASSCElls S. A post-mortem study of changes encountered in the Knee Joint of the Aged. J Bone Jt Surg 1969; 51A: 1037.

11 Goodfellow J., Hungerford D S, Woods C. Patellofemoral Joint Mechanics and Pathology, 2. Chondromalacia Patellae. Br J Bone Jt Surg 1976; 58B 3: 291-299.

12 INSALL J: Current concepts review, patella pain. J Bone Jt Surg 1982; 64A. 1: 147-152.

13 Brown Crosby E, INSALL J. Recurrent dislocation of the Patella. Relation of treatment to Osteoarthrosis. I Bone Jt Surg 1976; 58A: 19-13.

14 Bentley G. Chrondromalacia Patellae. J Bone Jt Surg 1970; 52A. 2: 221-232.

15 BjoRKSTROM S., Goldie I. A study of the Arterial Supply in the Patella in the normal state, in Chondromalacia Patellae and in Osteo-arthrosis. Acta Orthop Scand 1980; 51 : 63-70.
16 Lund F, Nilsson B E. Radiological Examination of Chondromalacia Patellae. Acta Radiol Diagnoses $1980 ; 21: 413-416$.

17 ABERNETHY $\mathrm{P}$ J et al. Is Chrondromalacia a Separate Clinical Entity? $\mathrm{Br} J$ Bone Jt Surg 1978; 60B. 2: 205-210.

18 Leading Article. Chondromalcia Patellae. $\mathrm{Br} \mathrm{Med} J$ 1981; 282: 1014

19 Radin E. A Rational Approach to the Treatment of Patellafemoral Pain. Clin Orthop and Related Res 1979; 144: 107-109.

20 Ficat M D et al. Chondromalacia Patellae. A System of Classification. Clin Orthop and Related Res 1979; 144: 55-62.

21 REPO $\mathrm{R}$ U et al. Survival of Articular Cartilage after Controlled Impact. J Bone Jt Surg 1977; 59A. 8: $1058-1076$.

22 DARracotT J, VernoN Roberts B. Bony changes in "Chondromalacia Patellae". Rheu and Phys Med 1971; 11: 175-179.

23 Leading Article. Biomechanical Troubles of the Patella. Lancet 1981; May 16th: 1088-1089.

24 LyNCH P, Oelman B J. Mortality from Coronary Heart Disease in the British Army Compared with the Civilian Population. $B r$ Med J 1981; 283: 405407.

25 MARCHANT A C et al Roetgenographic Analysis of Patellofemoral Congruence. J Bone Jt Surg 1974t 56A: 1391-1396.

26 FicAT R P, Hungerford D S. Disorders of tho Patellafemoral Joint. Baltimore, Williams and Wilkins 1977; 64.

27 AglietTI P, Cerulli G. Chondromalacia and re $\overline{\bar{\rho}}$ current subluxation of the Patella. A Study of Malalignment, with some indications for radioet graphy. Ital J Orthop and Trauma 1979; Aug 5th? 187-201.

28 Fox $T$ A. Displasia of the Quadriceps Mechanismo Hypoplasia of the Vastus Medialis Muscle aP related to the Hypermobile Patella Syndrome. Sur Clin N Am 1975; 55: 1.99-226.

29 Reider B, Marshall J, Warran R. Clinicab Characteristics of Patella Disorders in Youth Athletes. Am J Sports Med 1981; 4: 270-274.

30 ReILly D, MARTENS M. Experimental Analysis of Quadriceps Muscle Force and Patellofemoral Joint Reaction Force in various activities. Acta Orthop Scand 1972; 43: 126-137.

31 Williams $J$ G P. Vastus Medialis Re-education in the Management of Chondromalacia Patellas. Med Aspects of Sports 1974; 19-23.

32 OUTERBRIDGE R E, DUNLOP J. The problem of Chondromalacia Patella. Clin Orthop 1975; 110: 177-194.

33 RoAch J E et al. Comparison of the effects of steroid, aspirin and sodium salicylate on Articular Cartilage. Clin Orthop 1975; 106: 350-356.

34 RuBACABY G E. Inheritable Chondromalacia of the Patella. J Bone and $J t$ Surg 1963; 45A.8: 16851688. 